\title{
An overview of the methodological aspects and policy implications of willingness-to-pay studies in oral health: a scoping review of existing literature
}

\author{
Navid Saadatfar and Mohammad Pooyan Jadidfard*
}

\begin{abstract}
Background: Demands for dental services seem to be beyond the capacities of most healthcare systems these days. Patient preferences have been increasingly emphasized to be considered in the joint decision-making process. Willingness-to-pay (WTP) is a recommended method for measuring the utility of health services; increasingly being used in recent decades. Taking these points into consideration, this article aims to provide an overview of the methodological aspects and policy implications of WTP studies in the field of oral health.
\end{abstract}

Methods: The research was conducted in ISPOR, PubMed and Google Scholar databases. In addition, reference lists of included articles were checked to identify the relevant studies. All studies published were included that were in the English language and reported using WTP for oral health-related goods and services. A data-charting form was developed by a focus group discussion panel of seven experts to derive the main methodological aspects of WTP. Also, Core policy suggestions were categorized through thematic content analysis of the included papers.

Results: The search strategy yielded 389 studies of which 52 were included. WTP studies in oral health show an increasing trend in global publications. The UK and Canada have a greater share in published material than in any other country. The dominant field of these researches is in restorative and prosthetic dentistry, and a wide range of different methodological aspects was documented. Policy suggestions were categorized in three main themes: (A) setting new tariffs or subsidizing the item, (B) provision of the item due to population preferences, and (C) improving literacy regarding the item.

Conclusions: An urgent need for a common framework regarding the design of WTP studies in dentistry seems paramount. Some policy suggestions seem not to be applicable, perhaps due to insufficient familiarity of the researchers with the complexities of the public policymaking process.

Keywords: Health service, Oral health, Dentistry, Willingness-to-pay, Discrete choice experiment, Patient preference

*Correspondence: pooyan_mj@yahoo.com

Department of Community Oral Health, School of Dentistry, ShahidBeheshti University of Medical Sciences, Shahid-Chamran Avenue, Evin, Tehran 19839, Iran

\section{Background}

In joint decision making between patient and health care providers, preferences of patients for proposed procedures are at least as important as clinical norms $[1,2]$. On the other hand, demands for dental services are beyond the capacities of healthcare systems particularly in a majority of low and middle income countries [3]. 
Policymakers and health care managers must be informed about the different types of health care benefits perceived by patients, as well as factors influencing their services utility, in order to allocate optimal resources and generate favorable incentives within the healthcare systems $[4,5]$. Patient valuations should include factors beyond service effectiveness, such as time span, discomfort, pain and anxiety [2].

"Willingness-to-pay" (WTP) is a systematic and trustworthy method in monetary terms to measure the benefit of a health care intervention [4]. WTP seeks to measure the preference strength of an individual for any desired intervention by calculating the maximum amount of money they would sacrifice [6]. This is considered the manifestation of "direct democracy" in public policymaking [7]. The technique is primarily seen as an aid to place monetary value on health care programs and to compare them particularly with programs beyond the health sector $[8,9]$. WTP results can serve as the benefit wing of the economic evaluation (cost-benefit analysis) of a desired service, compared to other alternatives, which is strongly recommended as a critical input at the public level for decisions of allocation [10]. Therefore, WTP can help tailor dental treatment to individual patient valuations in a clinical practice, or help policymakers make informed decisions regarding resource allocation in the public sector and a priority setting across patient groups $[8,9]$.

WTP can be measured in two main ways: First, the "revealed preferences" approach which focuses on consumer behavior in the market and can be measured based on the information acquired from actual real market purchase of individuals and second, "stated preferences"; an indirect technique in which consumers are asked to explicitly state their WTP $[11,12]$. "Contingent Valuation" (CV) is a WTP survey asking participants to state their maximum WTP for a hypothetical item [11].

WTP can be elicited through interview or questionnaire but to achieve a more valid result it is recommended to use the face-to-face interview method [13]. WTP is versatile and can be used for inquiring about a public service such as water fluoridation for a state, or it can be a non-public service such as tooth filling service provisions in a private clinic. There are several methods to elicit the WTP amounts: (a) the "open-ended" questions in which respondents are asked to freely state their maximum amount of WTP, (b) the "Take-It-Or-Leave-It" (TIOLI) in which respondents agree or disagree with one proposed value, (c) the "bidding game" which starts with a single bid and increases or decreases in accordance with the respondent agreement till the maximum WTP is reached, (d) the "payment cards" in which respondents decide among cards presenting various values (If the cards are presented randomly the technique is called "shuffled payment cards"), and (e) "payment scales" in which respondents should select a range of values which consist of their desired maximum WTP [14]. These techniques can be used alone or combined with another elicitation method. The "open-ended" questions may lead to inaccurate answers because of "strategic bias" (this occurs when respondents behave strategically to influence the provision or funding of the asked item instead of expressing their true WTP amounts) [15]. Although the "bidding game" provides a "market-like" situation, it could suffer from "starting-point" bias (when the first presented amount affects the true maximum WTP of respondents) [15]. Need for a larger sample size and being susceptible to "starting-point" bias are disadvantages of TIOLI [15]. Although the "payment cards" method may be affected by "range bias" (effect of the range of amounts printed on the cards on the WTP amounts) it may not be suitable to be used in rural areas. Regarding the oral health field, some authors have recommended the "shuffled payment card method" as the most appropriate method to be applied for WTP studies [16].

Johannesson and Meltzer have recommended that investigation of societal WTP for health care should be a research priority [17]. WTP has also been suggested as the most appropriate method to measure patient preferences in dental care programs; both in publicly funded health care programs and in private insurance based plans [18-20].

Since 1999 when the first WTP study in dentistry was published, the number of such studies dramatically increased globally over two decades. A similar trend in $\mathrm{CV}$ studies on general health has been documented over a broader time span [21]. Therefore, it seems to be the proper time to have a critical overview of the existing WTP studies in oral health care to search for any implication of the results for oral health policymaking, and in the future help undertake more robust practical research. Although a valuable critical review probed methodological aspects of WTP studies related to clinical services [22], in the current review both clinical and non-clinical studies are included. In addition, this study aims to conduct a scoping review on the existing oral health literature on WTP studies with a particular focus on policy implications and to examine areas of shortcomings in this field.

\section{Methods}

We chose a scoping review methodology on WTP studies in the area of dentistry to explore all aspects of oral health services to derive diverse methodologies and policy implications. Our methods align with the 5-step methodological framework recommended by Arksey and 
O'Malley, albeit the first two steps are amalgamated [23]. The last search was done on March 15, 2020.

\section{Identification of research question and relevant research studies}

The main question of this scoping review was: "What are the methodological attributes and policy implications in dentistry of the existing WTP studies?" Keywords were selected under two main concepts: Oral health [with the main keywords but not confined to them; "oral health", "oral health care", dentistry, "dental care", "dental service(s)"] and willingness-to-pay [with the main keywords but not confined to them; "willingness-to-pay", WTP, "contingent valuation", "discrete choice experiment", DCE, patients' preferences, patients' valuations and patients' utilities]. Searches were conducted in PubMed, Google Scholar and the leading global International Society of Pharmacoeconomics and Outcomes Research (ISPOR) electronic databases with variations, and a combination of the keywords under two main aforementioned concepts. Reference lists of published oral health WTP articles were checked to identify relevant studies. The research question, search strategy and aim of the study were designed and discussed by both authors of the present study. Navid Saadatfar (NS) searched, removed duplicated articles, matched the obtained papers containing eligibility criteria, and then, extracted the data from the included papers. Mohammad Jadidfard revised the results and interpreted the data.

\section{Study selection}

Potential studies published in English reporting WTP for oral health related goods and services were considered in this review including original articles, online available dissertations and official reports. No restrictions involving terms of study time, location or methodological aspects of WTP were considered. Studies were excluded eliciting preference of participants using methods other than WTP (e.g. "time-trade-off") or studies using WTP without considering its effect on the oral health. Only reported article results of a dissertation were included in the review. If the data set was common in two or more articles, only one was included. Finally, two researchers independently reviewed all included studies.

\section{Data items and data charting process}

A data-charting form was developed to assess oral health WTP studies by focus group discussion of a panel of seven experts including three from Dental Public Health; these members are practicing clinicians, two health economists, one from health policy and one health care management specialist. The checklist items included sample size, sampling and WTP elicitation methods, desired goods and services, factors affecting the amount of the stated WTP and policy recommendations. Sampling methods were categorized as 'convenience sampling' and 'general population. The goods and services sections were categorized as 'public' and 'private' items. An item was considered public when its use by others did not limit the availability to any other person and when individuals could not be excluded from its use. Factors affecting WTP were charted if the article reported any statistically significant association in this regard. A data charting form was calibrated before being used by the authors. This data charting form was pretested by five randomly selected articles and resulted in a satisfactory level of agreement between the authors. The data charting process was done independently by NS.

\section{Collating, summarizing and presenting findings}

The methodological quality was not formally appraised as no specific checklist existed. Each paper was examined for any kind of policy implication inferred by the authors. A thematic content analysis method was used in order to identify the core policies in the documents. Contents of the documents were classified by an inductive-stepwise approach to the extract codes and final abstraction of the main themes. The included articles were examined and three final main themes (Core policies) were identified. All studies were investigated by both authors and any disagreements were resolved through discussion.

\section{Results}

\section{Overview of WTP studies in oral health}

The initial search resulted in identifying 343 articles using Google Scholar, 45 in PubMed and 1 in ISPOR and of which 52 were included in this review (48 papers and 4 theses and official reports). Finally, included articles consisted of 12 descriptive studies and 40 correlational studies (studies that seek to calculate any association between variables and WTP). A flowchart of the searched studies is shown in Fig. 1. Twenty-seven out of 52 articles (52\%) were published following the onset of 2014. Figure 2 shows the frequency by year of all published oral health WTP studies included in this review from 1999 to the beginning of 2020. Three studies were executed simultaneously in two countries [24-26]; the UK and Canada published WTP studies in oral health more than any other country. Table 1 shows published WTP studies by continent and country.

Eight studies have elicited WTP for goods and services which were not commonly provided in the market at the time of those studies [2, 10, 27-32]. Twelve studies evaluated WTP for public services such as "universal dental insurance" or "water fluoridation" [26-29, 32-39], while 38 studies measured WTP for private services such 


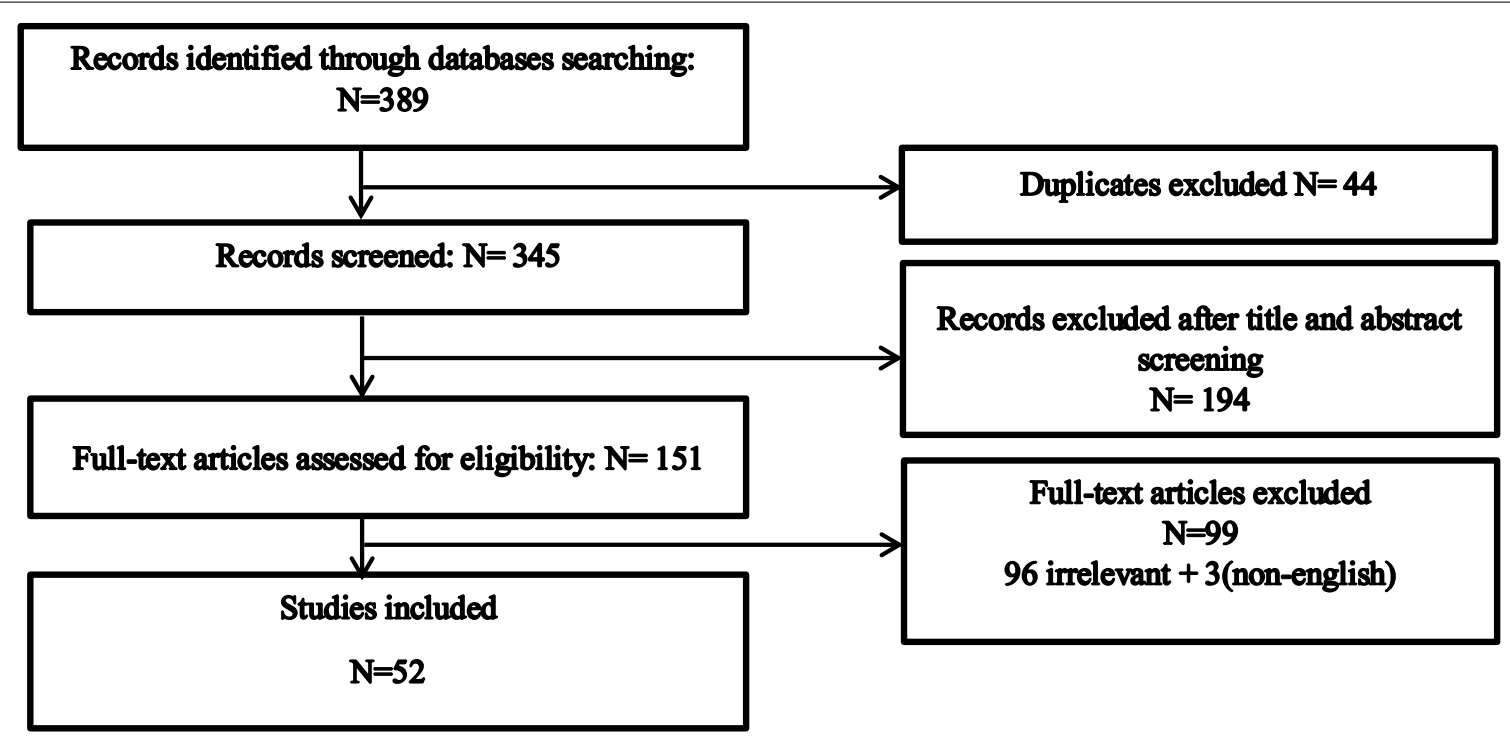

Fig. 1 Inclusion diagram

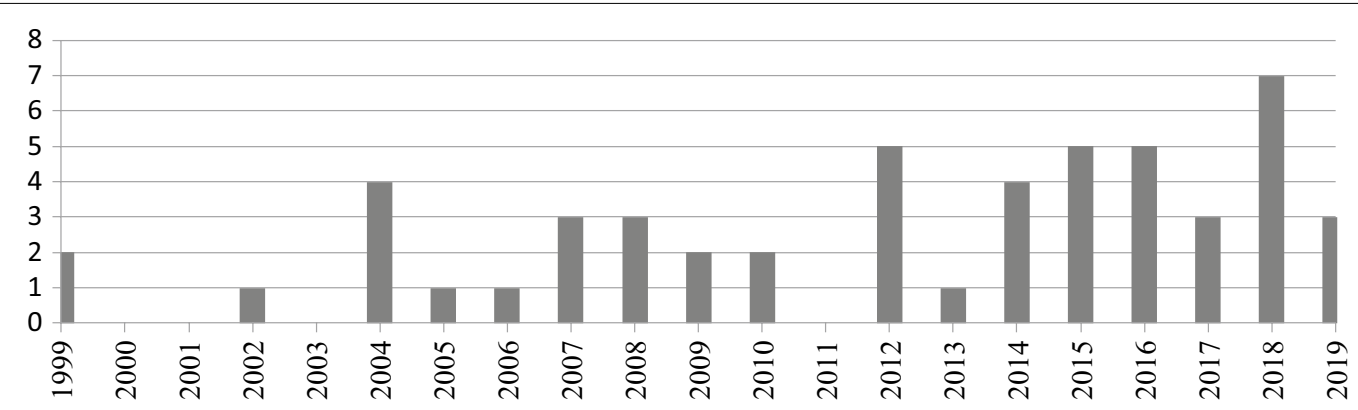

Fig. 2 Number of published willingness-to-pay articles in oral health by year

Table 1 Number of willingness-to-pay studies in each continent and country

\begin{tabular}{|c|c|c|c|c|}
\hline Continent and number of studies & Country & $\begin{array}{l}\text { Number of stud- } \\
\text { ies }\end{array}$ & Europe 26 studies (47\%) & UK \\
\hline \multirow[t]{8}{*}{ Asia 13 studies (23\%) } & KSA & 3 & & Italy \\
\hline & Hong Kong & 3 & & Norway \\
\hline & Iran & 2 & & Finland \\
\hline & Thailand & 2 & & Bulgaria \\
\hline & Singapore & 1 & & Croatia \\
\hline & & & & Scotland \\
\hline & India & 1 & & Switzerland \\
\hline & Philippines & 1 & & Germany \\
\hline \multirow[t]{2}{*}{ North America 11 studies (20\%) } & Canada & 8 & & Netherland \\
\hline & USA & 3 & & Sweden \\
\hline \multirow[t]{2}{*}{ Africa 2 studies (4\%) } & Kenya & 1 & Australia 1 study (2\%) & Australia \\
\hline & Tanzania & 1 & South America 2 studies (4\%) & Brazil \\
\hline
\end{tabular}

$(\%)=$ proportion to weight of each continent in the existing dentistry WTP studies 
as "root canal treatment" (RCT) or "implants". One study assessed WTP for 'waiting time before service utilization' [40] and another study elicited WTP for different states of oral health [36]. Table 2 shows the frequency of WTP studies by service type. Items evaluated in each study, details about the methodological aspects and policy suggestions are shown in Table 3.

\section{Overview of the methodological aspects of WTP studies in oral health}

Participant sample size broadly ranged from 16 to 1528 participants. A definite sample size calculation formula was reported in only eight studies [26, 38, 41-46]. Fifteen studies recruited samples from the general population $[2,6,25,27-29,32-34,39,47-51]$ and others used the convenience sampling method. Twenty-two studies had response rates of more than $70 \%$ and 21 reported no rates of participation. Seven studies elicited WTP of parents for paediatric service without taking into consideration children preferences [26, 34, 36, 37, 46, 52, 53].

Data gathering was done by either an interview (28 studies) or a questionnaire (22 studies). Two studies used both methods simultaneously $[38,51]$. To measure WTP, three studies used the Discrete Choice method [25, 29, 38], 11 studies used "open-ended" questions and one study reported no elicitation method in the original paper [54]. Twenty studies employed the "bidding-game". The remaining studies employed the WTP elicitation methods: "Payment Scale" $(\mathrm{n}=9)$, "Payment Card" $(\mathrm{n}=6)$ and "TIOLI" $(n=2)$. Five studies used two elicitation methods simultaneously [18, 40,47, 48, 55]. Twenty-eight studies declared the success rate of considered intervention as part of the scenarios presented to participants. Pretesting of the tool designed to elicit WTP amounts was done in 16 studies and, according to the authors, 5 studies were considered pilot studies [27, 32, 35, 37, 56].

Table 2 Number of willingness-to-pay studies by each type of dental interventions

\begin{tabular}{ll}
\hline Field of study & Number \\
\hline Restorative and prosthodontics & 10 \\
Oral health care schemes or insurance & 9 \\
Orthodontics & 8 \\
Combination of two or more fields & 8 \\
Preventive interventions & 7 \\
Oral medicine (anesthetic drugs or injection methods) & 3 \\
Special care (dentin regeneration, fear treatment, sonic & 3 \\
toothbrush) & 2 \\
Endodontics & 1 \\
Periodontics & 1 \\
Oral surgery & 1 \\
\hline
\end{tabular}

Only eight studies in the design of their research explicitly reported any notion of preparation for exclusive bias prevention of the WTP method such as "starting-point" and "strategic" biases [6, 28, 32, 35, 47-49, 57].

\section{Overview of policy implications of WTP studies in oral health}

Forty-one studies assessed participant characteristics influencing the stated amount of WTP. Of 40 studies 24 explored the association between "income" and WTP, and found a significant correlation between the two, among which only 6 studies made an adjustment of WTP results based on the different income groups. Furthermore, "age" (in 15 studies), "education" (in 13), "experience of receiving dental care" (in 7), "gender" (in 7) and "perceived importance of oral health" (in 4) showed WTP amounts to have a statistically significant correlation.

Sixteen articles (30\%) proposed at least one suggestion pertaining to policymaking. These recommendations can be categorized in three main classes: (A) setting new tariffs or subsidizing some services for the whole population or special groups (e.g. exemption from patient payment) -7 recommendations [10, 33, 34, 37, 47, 50, 58]. (B) WTP as a direct indicative of participant demand, where 7 recommended direct provision of the service by the public sector or its inclusion within the basic benefit package of any form of public insurance in order to better fit the healthcare system to the patient preferences [32, 38, 39, 45, 45, 47]. (C) Government or professional communities promotion of oral health literacy by giving relevant information for public consumption in order to improve perceptions regarding oral health [care] and healthcare system characteristics -3 recommendations $[24,42,59]$.

\section{Discussion}

Although representative samples of the general population are recommended in WTP studies, especially for consequential allocation decisions, most studies have used convenience samples. More opportunities may have arisen to undertake participant face-to-face active communication interviews accompanied by more detailed information regarding the desired service(s). Some studies elicited parental WTP for paediatric services [26, 34, $36,37,46,52,53]$. It is worth mentioning that these case results cannot be indicative of patient (child) perceptions, feelings and utilization of services which is an important aspect of the WTP method. Moreover, lack of standard sample size calculation formulas in dentistry has remained a common pitfall in WTP studies. Pretesting was not done in a majority of the studies $(60 \%)$ which is consistent with the findings of the previous review study [22]. 


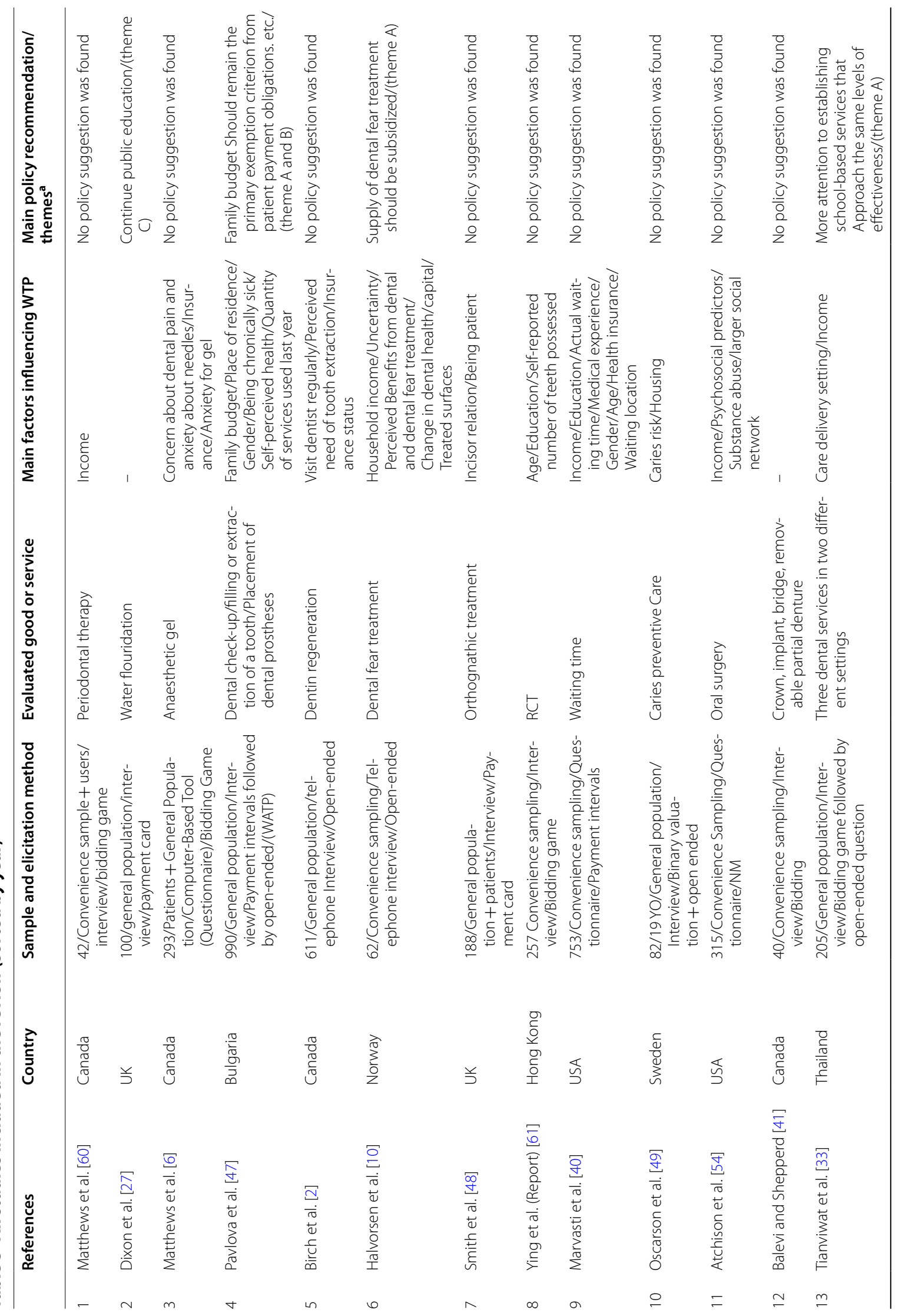




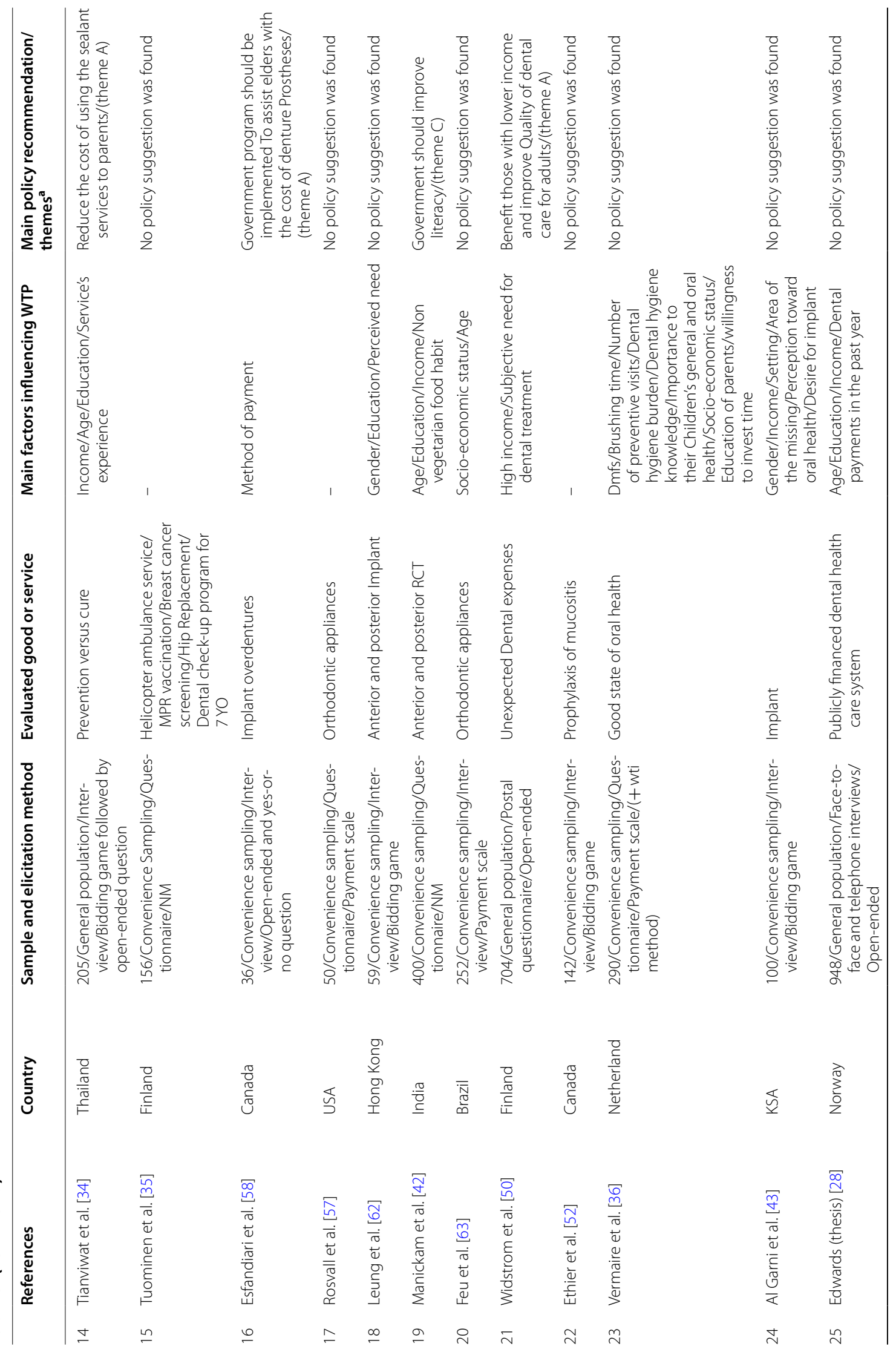




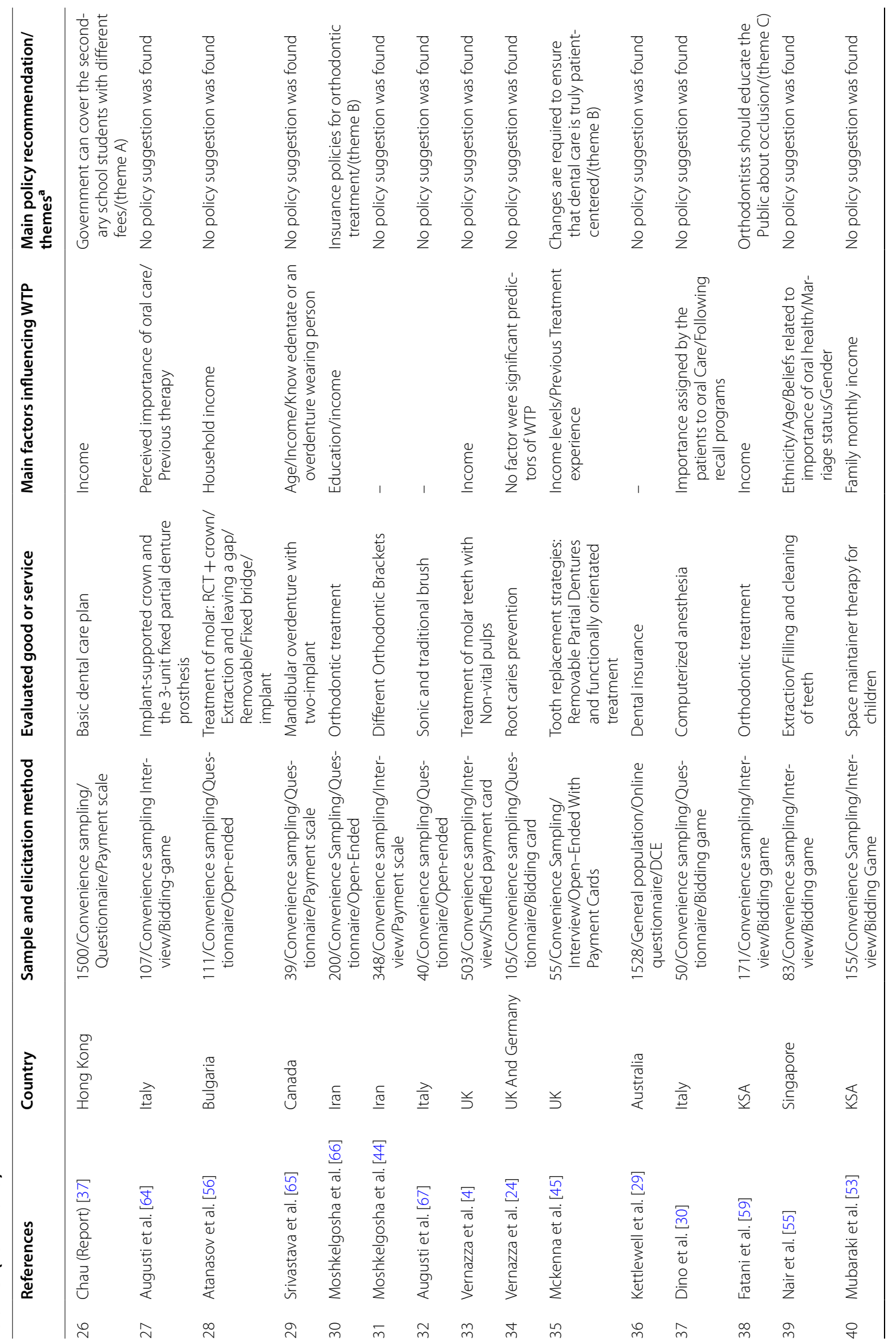




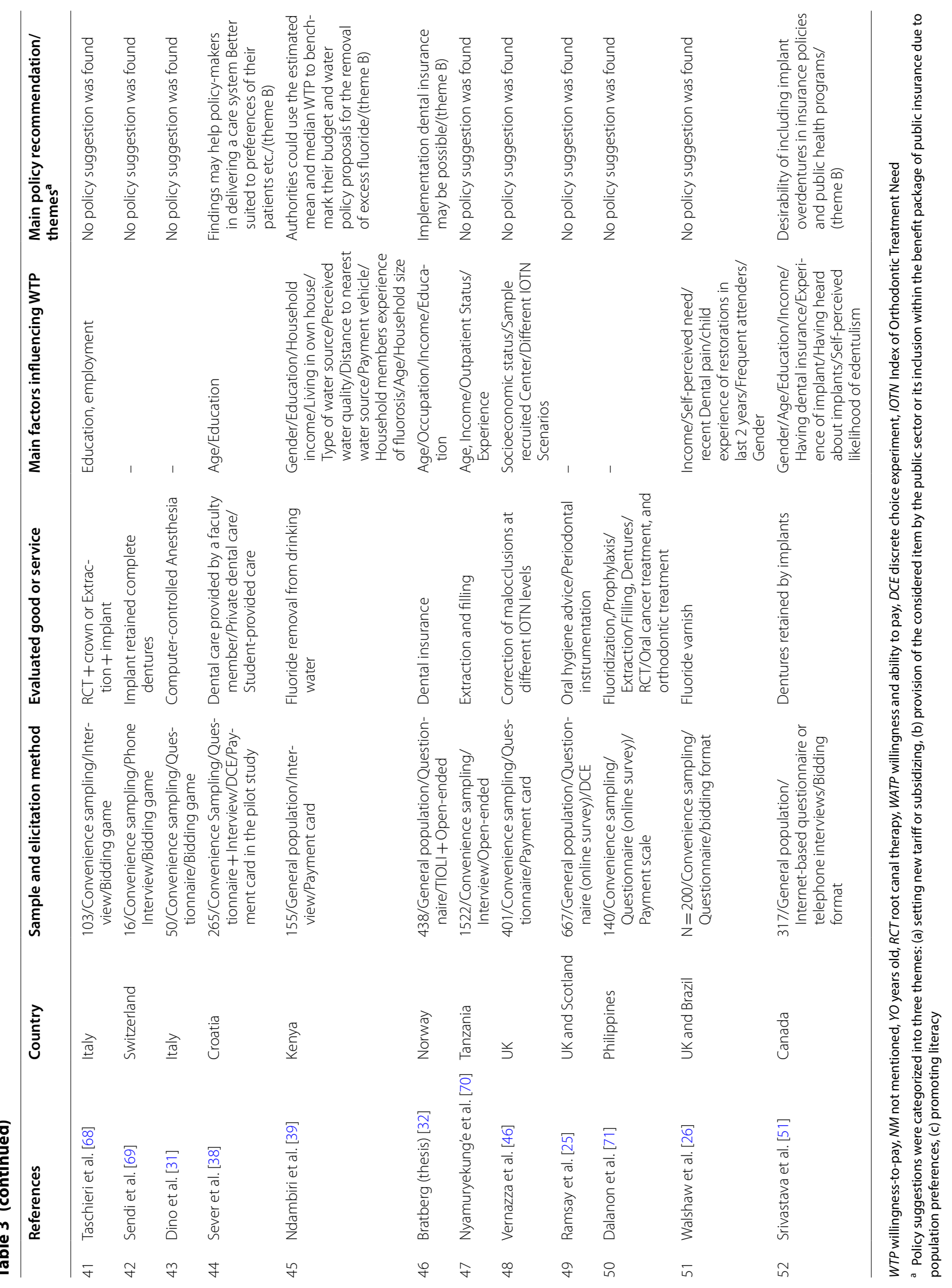


Cultural as well as health system attributes (including the predominant payment method) are two critical points to be undertaken in designing WTP studies in any setting. For example, although the 'shuffled payment card' is more likely to elicit true WTP amounts [16], it has been shown that the 'bidding-game' may be more suitable in developing countries [72]. In most of the studies, due to the unclear or inadequate details about contextual attributes in WTP reports, we are not aware of such considerations given in the design of these studies. Another limitation of this review was not identifying, by critical appraisal, the high-quality studies. According to the included studies in this review, the "bidding game" is the predominant method for eliciting WTP in the oral health field. This finding is consistent with previous oral health review articles [22].

In the majority of previous review article studies (57\%) which analyzed the association between income and WTP amounts, have reported a statistically significant association; indicating a direct correlation between 'ability' and 'willingness to pay' [22]. A possible advantage of WTP studies that researchers can investigate is whether or not people in higher income groups tend to prefer one option more frequently than do those in lower income groups [7]. If WTP results are to be used as inputs for equitable resource allocation decisions, they should be adjusted according to the income differences, otherwise WTP estimations may lead to skewed resource allocations favoring the higher income levels of society [73]. Reporting the WTP amounts as a percentage of income is recommended for this purpose [74].

In all 13 studies which reported a statistically significant association between WTP values and education level, higher education was associated with higher WTP amounts. In the health field, the positive effect of education level on WTP values was previously shown in a literature review on WTP studies regarding diagnostic technologies in healthcare [75]. In a majority of the included studies which reported a statistically significant association between gender and WTP amounts (5 of 7), females exhibited higher WTP amounts This finding is consistent with the results of the previous review study [22].

The net benefit of a service to a society is evaluated by comparing it to its costs [11]. Only 31 studies of the studies reviewed have made such comparisons between benefits (WTP amounts) and real market prices or service costs.

Some authors presumed WTP as an amount which will be precisely paid by participants in real-life circumstances [10, 33, 34, 37, 47, 50, 58], whereas many studies have shown a significant overstatement in WTP figures due to hypothetical bias (potential difference between individual decisions in the real market and a hypothetical situation) [76-80]. Some studies have shown the potential of understatement in WTP amounts, especially in case of private goods and services [81].

A few authors have suggested that services be funded from public resources through either direct provision of that service by the public sector (government), or its inclusion within a benefit package through a national or social health insurance [32, 38, 39, 45, 45, 47]. Researchers should be aware of the part-whole bias (different values elicited for an item depending on whether it is valued solely, or as a part, in a more inclusive package) [82] in WTP studies which can magnify the utility of the service [83]. Even if the biases are fully prevented and we view WTP as a true proxy of population demand, still a suggestion needs further necessary criteria for it to be taken under consideration. For example, cost burden for a household, relative cost-effectiveness and socio-economic status of the potential consumers are just three of the important factors in deciding whether to finance a service under insurance coverage [84].

Some authors concluded from WTP results that health literacy should be improved within the population [24, $42,59]$. It seems that in these cases, the WTP method is reduced to an attitude assessment tool, whereas the WTP method could have more practical implications.

In this study Scopus and Web of science databases were not used and access to grey literature or personal communications was nonexistent. In future reviews of WTP studies in oral health, quality appraisal of conducted studies can unveil more details about the methodological aspects.

\section{Conclusions}

In order to apply WTP studies to allocation purposes (as the benefit wing of cost-benefit analysis), there should be a consistency in the design of WTP studies [11], otherwise, WTP results are reduced to comparisons between desired services, when at least two choices have been considered, and this seriously limits the generalizability of the studies. Though no systematic and defined quality appraisal was done in this review, it appears that the majority of WTP studies in the field of oral health suffer from several deficits in some parts of the design such as sample size, representing samples, dealing with potential biases and pretesting. According to the current body of literature, the generalizability of oral health WTP results remains questionable, particularly in higher level decision making. It is felt that researchers who are interested in conducting WTP surveys for dental services need to pay more attention not only to the methodological aspects of the WTP studies, but to health policy knowledge as well, in order to conduct well-built studies in connection with meaningful and pragmatic policy considerations. It can be deliberated that accompanying research-minded policymakers, policy-minded researchers are also needed. 


\section{Abbreviations}

WTP: Willingness-to-pay; CV: Contingent valuation; NM: Not mentioned; YO: Years old; RCT: Root canal therapy; WATP: Willingness and ability to pay; DCE: Discrete choice experiment; IOTN: Index of orthodontic treatment need; ISPOR: The leading professional society for health economics and outcomes research globally.

\section{Acknowledgements}

Not applicable.

\section{Authors' contributions}

The research question, search strategy and aim of the study were designed through discussion between both authors, NS searched and extracted the data from the included papers. MJ revised the results and interpreted the data. Discussion and conclusion were produced based upon a dialogue between authors. All authors read and approved the final manuscript.

\section{Funding}

This study did not receive any funding or financial support.

\section{Availability of data and materials}

All data generated or analysed during this study are included in this published article. All included articles in this review are available from NS on reasonable request.

\section{Ethics approval and consent to participate}

Not applicable.

\section{Consent for publication}

Not applicable.

\section{Competing interests}

The authors declare that they have no competing interests.

Received: 29 April 2020 Accepted: 29 October 2020

Published online: 12 November 2020

\section{References}

\section{$(*=$ articles included in the review)}

1. Fyffe HE, Kay EJ. Assessment of dental health state utilities. Commun Dent Oral Epidemiol. 1992;20(5):269-73.

2. * *Birch S, Sohn W, Ismail Al, Lepkowski JM, Belli RF. Willingness to pay for dentin regeneration in a sample of dentate adults. Commun Dent Oral Epidemiol. 2004;32(3):210-6.

3. Kathmandu RY. The burden of restorative dental treatment for children in Third World countries. Int Dent J. 2002;52(1):1-9.

4. *Vernazza CR, Steele JG, Whitworth JM, Wildman JR, Donaldson C. Factors affecting direction and strength of patient preferences for treatment of molar teeth with nonvital pulps. Int Endod J. 2015;48(12):1137-46.

5. De Bekker-Grob EW, Hol L, Donkers B, Van Dam L, Habbema JD, Van Leerdam ME, Kuipers EJ, Essink-Bot ML, Steyerberg EW. Labeled versus unlabeled discrete choice experiments in health economics: an application to colorectal cancer screening. Value Health. 2010;13(2):315-23.

6. *Matthews D, Rocchi A, Gafni A. Putting your money where your mouth is. Pharmacoeconomics. 2002;20(4):245-55.

7. Donaldson C. Willingness to pay and publicly funded health care: contradiction in terms? InSeminar Briefings 2011 Nov 1 (No. 000173). Office of Health Economics.

8. Diener A, O'Brien B, Gafni A. Health care contingent valuation studies: a review and classification of the literature. Health Econ. 1998;7(4):313-26.

9. Olsen JA, Smith RD. Theory versus practice: a review of 'willingness-topay'in health and health care. Health Econ. 2001;10(1):39-52.

10. *Halvorsen B, Willumsen T. Willingness to pay for dental fear treatment. Eur J Health Econ. 2004;5(4):299-308.
11. Smith RD, Harris $A H$, Olsen JA. A review of methodological issues in the conduct of WTP studies in health care II: administration of a CV survey. West Heidelberg: Centre for Health Program Evaluation; 1999.

12. Carson RT, Hanemann WM. Contingent valuation. Handb Environ Econ. 2005;1(2):821-936

13. Calder J, Overland J, Uttal T, Richter-Menge J, Rigor I, Crane K. National Oceanic and Atmospheric Administration (NOAA) arctic climate change studies: a contribution to IPY. AGUFM. 2004;2004:C21A-0960.

14. Frew EJ, Whynes DK, Wolstenholme JL. Eliciting willingness to pay: comparing closed-ended with open-ended and payment scale formats. Med Decis Mak. 2003;23(2):150-9.

15. Venkatachalam L. The contingent valuation method: a review. Environ Impact Assess Rev. 2004;24(1):89-124.

16. Smith RD. It's not just what you do, it's the way that you do it: the effect of different payment card formats and survey administration on willingness to pay for health gain. Health Econ. 2006;15(3):281-93.

17. Johannesson M, Meltzer D. Some reflections on cost-effectiveness analysis. Health Econ. 1998;7(1):1-7.

18. Matthews DC, Gafni A, Birch S. Preference based measurements in dentistry: a review of the literature and recommendations for research. Commun Dent Health. 1999;16(1):5-11.

19. Cunningham SJ, Hunt NP. Relationship between utility values and willingness to pay in patients undergoing orthognathic treatment. Commun Dent Health. 2000;17(2):92-6.

20. Birch S, Ismail Al. Patient preferences and the measurement of utilities in the evaluation of dental technologies. J Dent Res. 2002;81(7):446-50.

21. Smith RD, Sach TH. Contingent valuation: what needs to be done? Health Economics, Policy and Law. 2010;5(1):91-111.

22. Tan SH, Vernazza CR, Nair R. Critical review of willingness to pay for clinical oral health interventions. J Dent. 2017;1(64):1-2.

23. Arksey H, O'Malley L. Scoping studies: towards a methodological framework. Int J Soc Res Methodol. 2005;8:19-32.

24. *Vernazza CR, Wildman JR, Steele JG, Whitworth JM, Walls AW, Perry R, Matthews R, Hahn P, Donaldson C. Factors affecting patient valuations of caries prevention: using and validating the willingness to pay method. J Dent. 2015:43(8):981-8.

25. *Ramsay CR, Clarkson JE, Duncan A, Lamont TJ, Heasman PA, Boyers D, Goulão B, Bonetti D, Bruce R, Gouick J, Heasman L. Improving the Quality of Dentistry (IQuaD): a cluster factorial randomised controlled trial comparing the effectiveness and cost-benefit of oral hygiene advice and/ or periodontal instrumentation with routine care for the prevention and management of periodontal disease in dentate adults attending dental primary care. Health Technology Assessment. 2018.

26. *Walshaw EG, Adam NI, Palmeiro ML, Neves M, Vernazza CR. Patients' and parents' valuation of fluoride varnish in the UK and Brazil. Oral Health Prevent Dent. 2019;17(3):211.

27. *Dixon S, Shackley P. Estimating the benefits of community water fluoridation using the willingness-to-pay technique: results of a pilot study. Commun Dent Oral Epidemiol. 1999;27(2):124-9.

28. * Edwards $\mathrm{CH}$. An evaluation of the socioeconomic viability of a dental health care reform in Norway: a willingness to pay approach. Master's thesis.

29. *Kettlewell N. Policy choice in a complicated health insurance market: Do people get it right?

30. *Re D, Fessi S, Augusti G, Augusti D. The patient's side: Willingness-to-pay index for computerized anesthesia.

31. *Re D, Del Fabbro M, Karanxha L, Augusti G, Augusti D, Fessi S, Taschieri S. Minimally-invasive dental anesthesia: patients' preferences and analysis of the willingness-to-pay index. J Invest Clin Dent. 2018;9(1):e12275.

32. *Bratberg I. Are youths aged 18-30 years willing to pay for dental insurance? A willingness-to-pay analysis. Master's thesis.

33. *Tianviwat $\mathrm{S}$, Chongsuvivatwong V, Birch S. Different dental care setting: does income matter? Health Econ. 2008a;17(1):109-18.

34. *Tianviwat $\mathrm{S}$, Chongsuvivatwong V, Birch S. Prevention versus cure: measuring parental preferences for sealants and fillings as treatments for childhood caries in Southern Thailand. Health Policy. 2008b;86(1):64-71.

35. *Tuominen R. Evaluation of three methods assessing the relative value of a dental program. Acta Odontol Scand. 2008;66(2):82-7. 
36. *Vermaire JH, Van Exel NJ, Van Loveren C, Brouwer WB. Putting your money where your mouth is: parents'valuation of good oral health of their children. Soc Sci Med. 2012;75(12):2200-6.

37. *Chau, Man-ho, Jimmy. Dental care programme for Hong Kong secondary school students: parents' choices and willingness to pay (2014). https://hdl. handle.net/10722/206534.

38. *Sever I, Verbič M, Sever EK. Valuing the delivery of dental care: heterogeneity in patients' preferences and willingness-to-pay for dental care attributes. J Dent. 2018:1(69):93-101.

39. *Ndambiri H, Rotich E. Valuing excess fluoride removal for safe drinking water in Kenya. Water Policy. 2018;20(5):953-65.

40. *Marvasti A. A contingent valuation of customer delay in medical services. Eastern Econ J. 2006;32(1):31-45.

41. *Balevi B, Shepperd S. The management of an endodontically abscessed tooth: patient health state utility, decision-tree and economic analysis. BMC Oral Health. 2007;7(1):17.

42. *Manickam S, Selvakumar R, Devadason P. An economic analysis of willingness to pay for root canal treatment for dental caries in Thoothukudi District, Tamilnadu. J Indian Assoc Public Health Dent. 2010;8(16):208.

43. *Al Garni B, Pani SC, AlMaaz A, Al Qeshtaini E, Abu-Haimed H, Al SK. Factors affecting the willingness to pay for implants: a study of patients in Riyadh, Saudi Arabia. Dent Res J. 2012;9(6):719.

44. * Moshkelgosha V, Salahi MA, Rostami S. Evaluation of perceived acceptability, beauty and value of different orthodontic brackets. J Dent Biomater. 2015;2(1):33-8.

45. *McKenna G, Tada S, Woods N, Hayes M, DaMata C, Allen PF. Tooth replacement for partially dentate elders: a willingness-to-pay analysis. J Dent. 2016;1 (53):51-6

46. *Vernazza CR, Anderson L, Hunter Al, Leck HC, O'Connor SD, Smith GR, Stokes RJ, Rolland SL. The value of orthodontics: do parents' willingness-topay values reflect the IOTN? JDR Clin Transl Res. 2018:3(2):141-9.

47. *Pavlova M, Groot W, Van Merode G. Willingness and ability of Bulgarian consumers to pay for improved public health care services. Appl Econ. 2004;36(10):1117-30.

48. ${ }^{*}$ Smith AS, Cunningham SJ. Which factors influence willingness-to-pay for orthognathic treatment? Eur J Orthod. 2004;26(5):499-506.

49. * Oscarson N, Lindholm L, Källestål C. The value of caries preventive care among 19-year olds using the contingent valuation method within a costbenefit approach. Commun Dent Oral Epidemiol. 2007;35(2):109-17.

50. *Widström E, SeppäläT. Willingness and ability to pay for unexpected dental expenses by Finnish adults. BMC Oral Health. 2012;12(1):35.

51. *Srivastava A, Esfandiari S, Madathil SA, Birch S, Feine JS. Willingness to pay for mandibular overdentures: a societal perspective. JDR Clin Transl Res. 2020;5(1):30-9.

52. *Ethier MC, Regier DA, Tomlinson D, Judd P, Doyle J, Gassas A, Naqvi A, Sung L. Perspectives toward oral mucositis prevention from parents and health care professionals in pediatric cancer. Support Care Cancer. 2012;20(8):1771-7.

53. *Mubaraki S, Abubotain S, AlDhahri S, AlGhamdi R, AlOtaibi R, Pani S. Willingness of parents to pay for space maintainer therapy for their children. EC Dental Sci. 2017:9:94-8.

54. *Atchison KA, Gironda MW, Black EE, Schweitzer S, Der-Martirosian C, Felsenfeld A, Leathers R, Belin TR. Baseline characteristics and treatment preferences of oral surgery patients. J Oral Maxillofac Surg. 2007;65(12):2430-7.

55. *Nair R, Yee R. Differences in willingness to pay for an extraction, a filling, and cleaning teeth at various levels of oral health-related quality of life, as measured by oral impacts on daily performance, among older adults in Singapore. Singapore Dent J. 2016;1(37):2-8.

56. *Atanasov N, Dimitrova D, Stoyanova R, Alexandrova M, Dimova R, Lefterova B. stated preferences and willingness to pay for molar treatment: results of pilot study. Trakia J Sci. 2014;12(1):403-7.

57. *Rosvall MD, Fields HW, Ziuchkovski J, Rosenstiel SF, Johnston WM. Attractiveness, acceptability, and value of orthodontic appliances. Am J Orthod Dentofac Orthop. 2009;135(3):276-e1.

58. *Esfandiari S, Lund JP, Penrod JR, Savard A, MarkThomason J, Feine JS. Implant overdentures for edentulous elders: study of patient preference. Gerodontology. 2009;26(1):3-10.

59. *Fatani EJ, Al-Yousef SK. Willingness to pay for orthodontic treatment in Kingdom of Saudi Arabia, Riyadh Province. Saudi J Oral Sci. 2016;3(2):104
60. *Matthews DC, Birch S, Gafni A, DiCenso A. Willingness to pay for periodontal therapy: development and testing of an instrument. J Public Health Dent. 1999;59(1):44-51.

61. *Ying CK, McGrath AD, Yin MN, On LN. Willingness to pay (WTP) for root canal treatment: An economic analysis.

62. *Leung KC, McGrath CP. Willingness to pay for implant therapy: a study of patient preference. Clin Oral Implant Res. 2010;21 (8):789-93.

63. *Feu D, Catharino F, Duplat CB, Capelli JJ. Esthetic perception and economic value of orthodontic appliances by lay Brazilian adults. Dent Press J Orthod. 2012;17(5):102-14.

64. *Augusti D, Augusti G, Re D. Prosthetic restoration in the single-tooth gap: patient preferences and analysis of the WTP index. Clin Oral Implant Res. 2014;25(11):1257-64.

65. *Srivastava A, Feine JS, Esfandiari S. Are people who still have their natural teeth willing to pay for mandibular two-implant overdentures? I Invest Clin Dent. 2014;5(2):117-24.

66. *Moshkelgosha V, Golkari A. An evaluation of willingness to pay for orthodontic treatments in patients of Shiraz Dental School Clinic. J Oral Health Oral Epidemiol. 2015;2:35-43.

67. *Re D, Augusti G, Battaglia D, Giannì AB, Augusti D. Is a new sonic toothbrush more effective in plaque removal than a manual toothbrush. Eur $J$ Paediatr Dent. 2015;16(1):13-8.

68. * Re D, Ceci C, Cerutti F, Del Fabbro M, Corbella S, Taschieri S. Natural tooth preservation versus extraction and implant placement: patient preferences and analysis of the willingness to pay. Br Dent J. 2017;222(6):467.

69. * Sendi P, Bertschinger N, Brand C, Marinello CP, Bucher HC, Bornstein MM. Measuring the monetary value of dental implants for denture retention: a willingness to pay approach. Open Dent J. 2017;11:498.

70. *Nyamuryekung'e KK, Lahti SM, Tuominen RJ. Patients' willingness to pay for dental services in a population with limited restorative services. Commun Dent Health. 2018:35(3):167-72.

71. *Dalanon J, Diano LM, Esguerra R, Belarmino MP, Docor MR, Rodis OM, Locsin R, Matsuka Y. The Cebuano Mothers'Willingness to Pay for Dental Healthcare.

72. Dong H, Kouyate B, Cairns J, Sauerborn R. A comparison of the reliability of the take-it-or-leave-it and the bidding game approaches to estimating willingness-to-pay in a rural population in West Africa. Soc Sci Med. 2003;56(10):2181-9.

73. Donaldson C. Eliciting patients'values by use of'willingness to pay': letting the theory drive the method. Health Expect. 2001;4(3):180-8.

74. Damschroder $\sqcup$, Ubel PA, Riis J, Smith DM. An alternative approach for eliciting willingness-to-pay: a randomized Internet trial.

75. Lin PJ, Cangelosi MJ, Lee DW, Neumann PJ. Willingness to pay for diagnostic technologies: a review of the contingent valuation literature. Value Health. 2013;16(5):797-805.

76. Cummings RG. Valuing environmental goods. An assessment of the contingent valuation method. 1986:104-7.

77. List JA, Gallet CA. What experimental protocol influence disparities between actual and hypothetical stated values? Environ Resource Econ. 2001;20(3):241-54.

78. Little J, Berrens R. Explaining disparities between actual and hypothetical stated values: further investigation using meta-analysis. Econ Bull. 2004:3(6):1-3.

79. Murphy JJ, Allen PG, Stevens TH, Weatherhead D. A meta-analysis of hypothetical bias in stated preference valuation. Environ Resource Econ. 2005;30(3):313-25

80. Hausman J. Contingent valuation: from dubious to hopeless. J Econ Perspect. 2012;26(4):43-56

81. Loomis JB. 2013 WAEA keynote address: strategies for overcoming hypothetical bias in stated preference surveys. J Agric Resour Econ. 2014;1:34-46.

82. Kahneman D, Knetsch JL. Valuing public goods: the purchase of moral satisfaction. J Environ Econ Manag. 1992;22(1):57-70.

83. Bateman I, Munro A, Rhodes B, Starmer C, Sugden R. Does part-whole bias exist? An experimental investigation. Econ J. 1997:107(441):322-32.

84. Jadidfard MP, Yazdani S, Khoshnevisan MH. Developing a policy guidance for financing dental care in Iran using the RAND Appropriateness Method. Commun Dent Health. 2013;30(4):227-33.

\section{Publisher's Note}

Springer Nature remains neutral with regard to jurisdictional claims in published maps and institutional affiliations. 